Submission ID: 43759

\title{
Analysis of Rock Saturation Character in the Heterogeneous Oil Reservoir of
} the Priobskoye Field Formation Ac10

I. Ratnikov* (OOO Neftecom), N. Yarkova (Coretest Service), E. Romanova (Coretest Service)

\section{SUMMARY}

The basic factors influencing the nature of non-uniform hydrocarbon $(\mathrm{HC})$ saturation of the bed $\mathrm{AC} 10$ are considered. The geological nature of heterogeneity depending on the degree of the reservoir properties variability is analyzed. It is also studied how microheterogeneity influences on the rocks saturation and also the character of the heterogeneity effect upon the physical properties is investigated. 


\section{Анализ характера насыщенности пород в неоднородном коллекторе пласта АС10 Приобского месторождения}

Ратников И.Б. (ООО «Нефтеком»), Яркова Н.С (ООО «Корэтест-Сервис»), Романова Е.Е (ООО «Корэтест-Сервис»)

\section{Введение}

В настоящее время все большее значение приобретает исследование неоднородности горных пород в нефтяной геологии, поскольку основные запасы нефти и газа сосредоточены в коллекторах с низкими фильтрационно-емкостными свойствами (ФЕС), осложненными неоднородностью строения. Наряду с решением вопросов методики, изучается влияние неоднородности пород-коллекторов на их емкостной потенциал, проницаемость, нефтенасыщенность, коэффициент вытеснения. Исследуется также картина передвижения водонефтяного контакта, способы увеличения нефтеотдачи пласта, что очень важно для успешной разработки месторождения. Перемещение водонефтяного контакта на границе «коллектор-неколлектор» существенным образом отличается от его передвижения в средней части коллектора. Отмеченные параметры пород-коллекторов без учета неоднородности весьма сложно оценить даже приблизительно. Рядом исследователей [1-4 и др.] проделана большая работа по учету геологической неоднородности при проектировании разработки нефтяных месторождений. Однако в теории и практике подсчета запасов углеводородного сырья этот вопрос остается менее изученным и ограничивается лишь определением коэффициентов, характеризующих неоднородность, и типизацией по ним нефтяных залежей [4].

В работах [6-8 и др.] неоднократно отмечено, что, по существу, все петрофизические признаки носят унаследованный характер литолого-фациальной изменчивости. Это обусловлено неоднородностью, сформировавшейся в процессе диагенеза осадочных пород, протекающих в разных точках геологической среды (ГС) по разному (в неодинаковых условиях). Как следствие, дальнейший ход эпигенеза «накладывается» на процесс диагенеза. Отсюда возникает унаследственность неоднородности горных пород, которая определяет изменчивость петрофизических (да не только) признаков.

\section{Обсуждение результатов}

Условия формирования пласта АC10 предполагают широкую изменчивость литологоминералогического состава и текстурно-структурных особенностей.

На рис. 1 представлено сопоставление данных ГИС с фотографиями керна в дневном и ультрафиолетовом свете для пород пласта АC10 Приобского месторождения. В приведённом интервале глубины общая эффективная толщина (Нэф) выделенная по ГИС составила 10,8 м, а по фотографиям керна в ультрафиолетовом (УФ) свете Нэф нефтенасыщенных прослоев составляет всего 6,2 м, что меньше на 42,6\%. Видно, что по фотографиям в дневном свете, керн пласта АC10 в основной массе однороден. Однако фотографии в ультрафиолетовом (УФ) свете проявили островное насыщение керна углеводородами (УВ). На фотографии в УФ чётко выделяются 2 зоны: яркое свечение (зона 1) и тёмное (зона 2).

Постараемся осмыслить, почему в визуально однородном, по фотографиям в дневном свете, керне проявляется островное насыщение УВ.

Литологически породы 1 зоны представлены песчаниками и алевролитами с глинистым и карбонатно-глинистым цементом, а 2 зоны - алевролитами с глинистым и карбонатным цементом. 


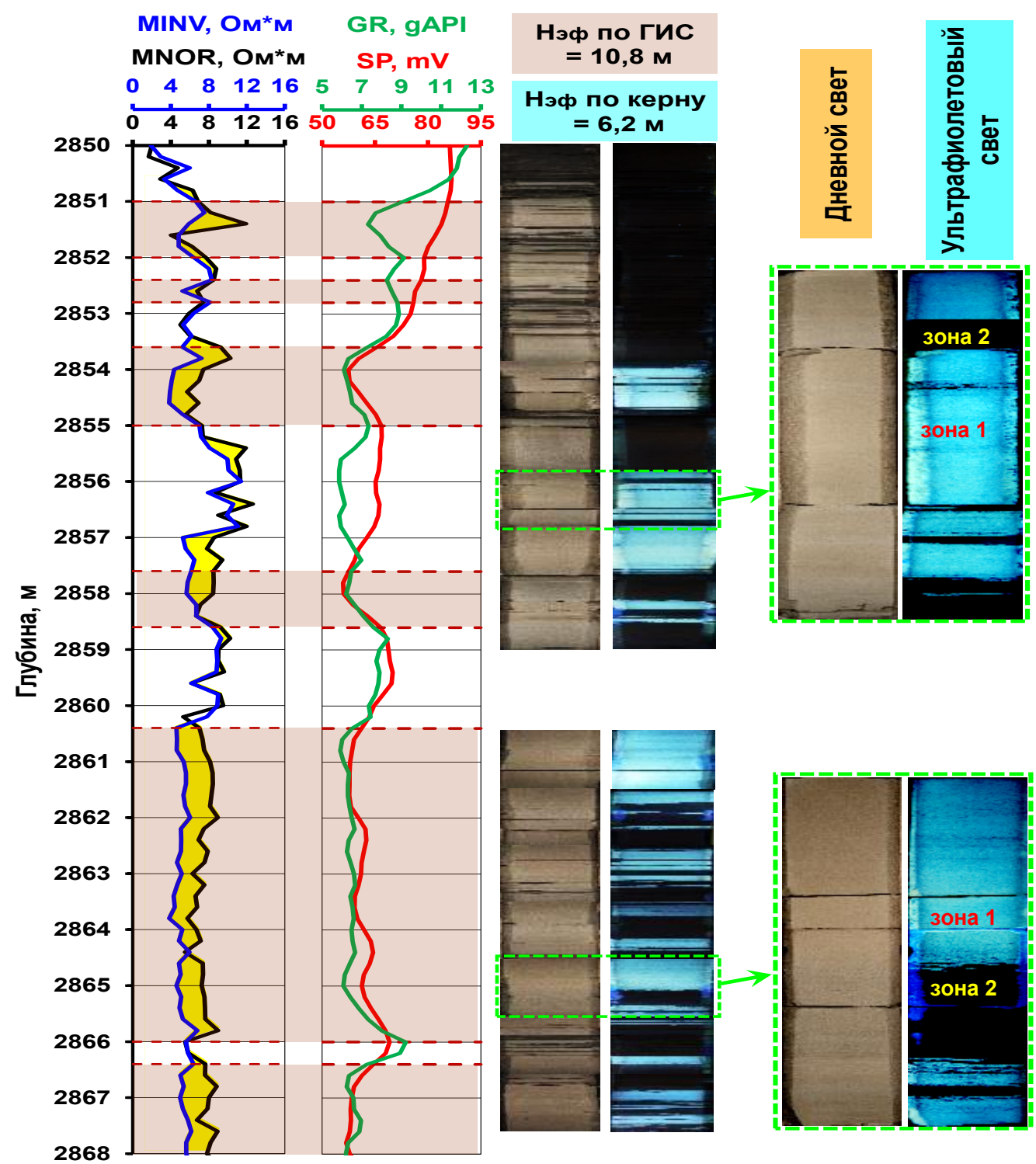

Рис. 1 Данные ГИС и фотографии керна в дневном и ультрафиолетовом свете

Для выявления природы неравномерной насыщенности коллектора УВ по выделенным зонам осуществлен совместный анализ результатов, полученных по размерам капиллярных каналов и пор, а также степени их заполнения глинистым и карбонатным материалом.

Размеры пор и поровых каналов и характер их распределения по величинам. являются одним из важных показателей в области петрофизики. От этих показателей во многом зависит распределение фаз в коллекторе. Петрофизические параметры зависят преимущественно от размера поровых каналов, из которых слагается поровое пространство. Известно, чем более неоднородны размеры поровых каналов коллектора, тем больше остаточная нефтенасыщенность и тем меньше коэффициент вытеснения. Это явление в глинизированных коллекторах обусловлено, прежде всего, эффектом Лапласа. [5]

С целью изучения особенностей структуры порового пространства по выделенным зонам выполнен анализ снимков растрового электронного микроскопа (РЭМ) (рис. 2 и 3). Анализ особенностей структуры порового пространства выявил, что породы 1 зоны имеют более крупные поры относительно пород 2 зоны. 


\section{EAGE}

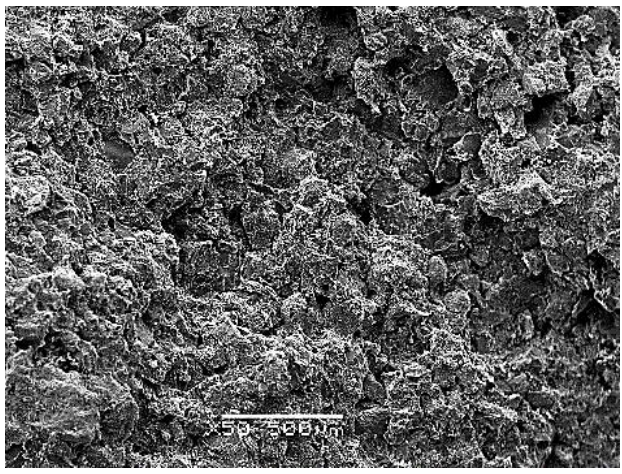

a

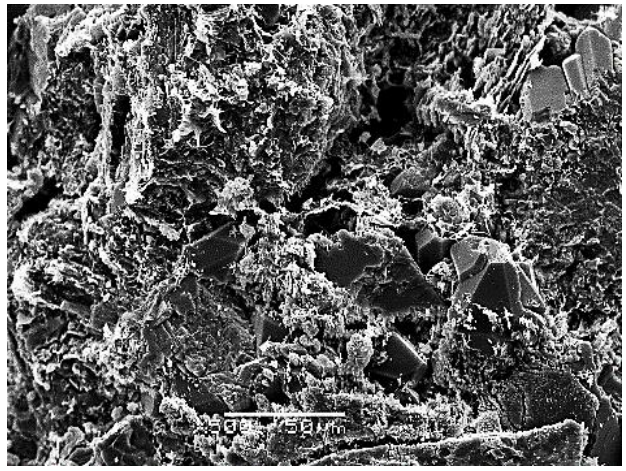

б

Pис. 2 Снимки РЭМ. Вид: а, б - общее строение породы и особенности структуры порового пространства, увеличение 50х и $500 x$ соответственно. На фото - зона 1.
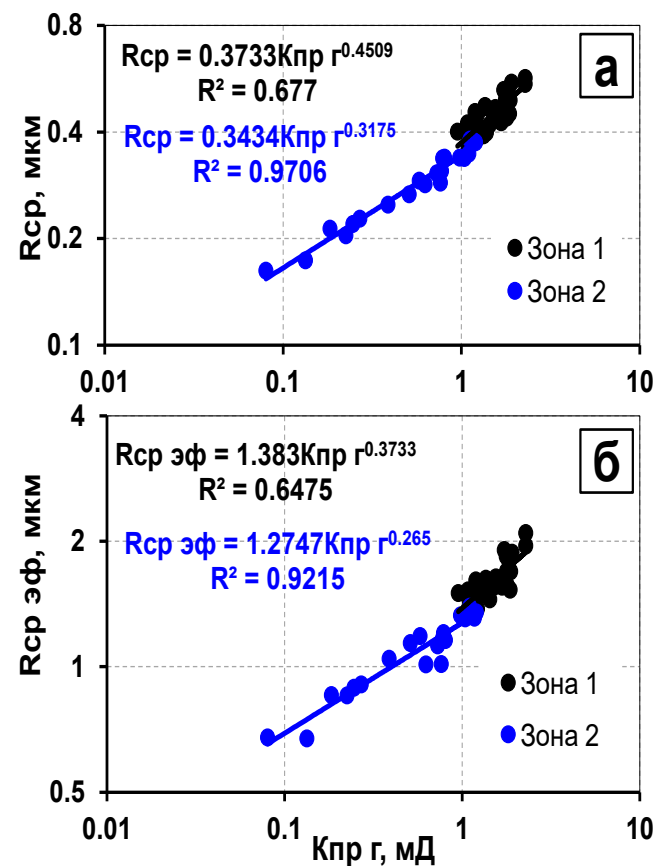

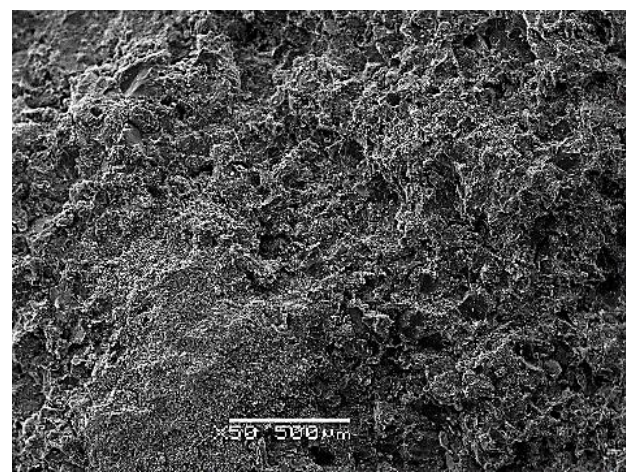

a

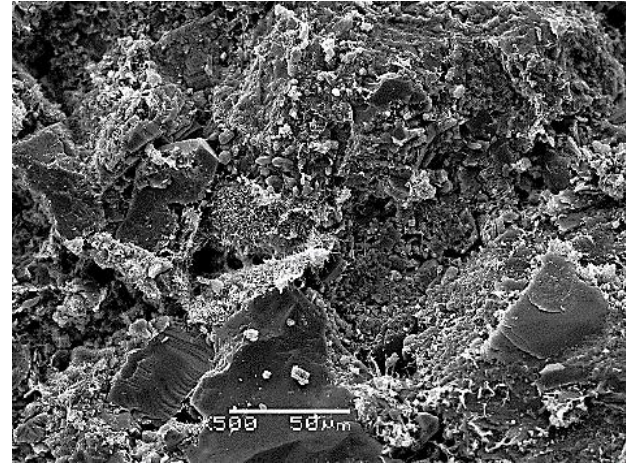

б

Pис. 3 Снимки РЭМ. Вид: а, б - общее строение породы и особенности структуры порового пространства, увеличение 50x и 500x соответственно. На фото - зона 2.
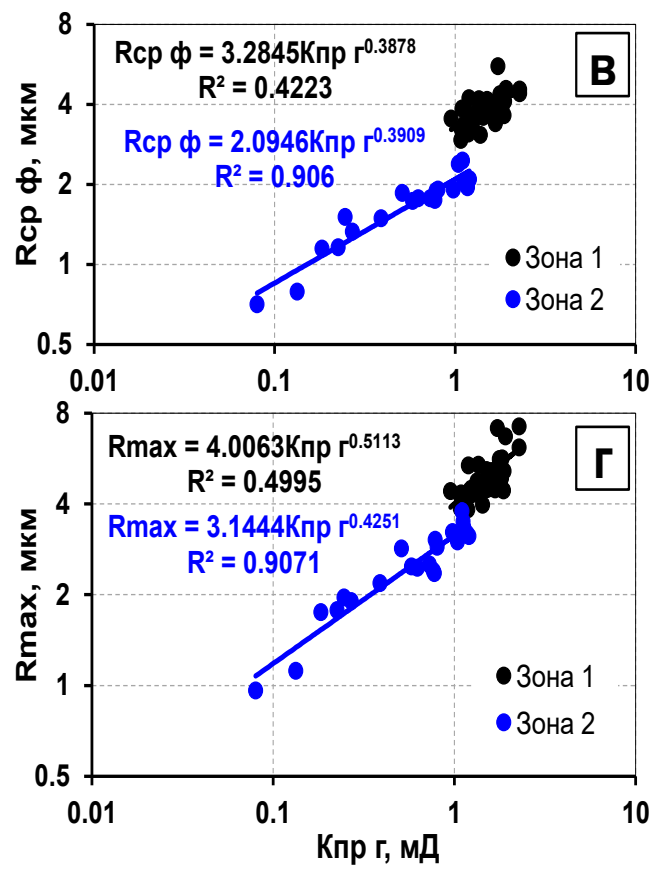

Puc. 4 Сопоставление среднего (Rcp) (a), среднего эффективного (Rcp эф) (б), среднего фильтрующего (Rcp ф) (в) и максимального (Rmax) радиусов поровых каналов $c$ абсолютной проницаемостью по газу (Кир г) 
Исследование структуры порового пространства показало, что породы 1 зоны обладают более лучшими фильтрующими каналами относительно пород 2 зоны. На основании результатов распределения поровых каналов и их участия в фильтрации жидкости методом статистических моментов были рассчитаны средние радиусы поровых каналов и выполнено их сопоставление с абсолютной проницаемостью по газу (рис. 4). Метод статистических моментов базируется на строгой вероятностной теории оценивания статистических характеристик. [5]

Анализ вещественного состава показал, что основополагающее влияние на размер фильтрующих каналов оказывает содержание глинистого и карбонатного материала в поровом пространстве пород.

Для более детального выяснения степени заполнения порового пространства пород глинистым и карбонатным материалом, был выполнен расчет коэффициента относительной глинистости и глинисто-карбонатности и выполнено их сопоставление с открытой пористостью. Степень заполнения порового пространства глинистым и карбонатным материалом для пород 1 зоны варьирует в пределах 35-54\% (42\%), а для пород второй зоны - 45-92\% (57\%).

\section{Выводы}

На основании проведённого анализа, мы приходим к выводу, что островное насыщение УВ пласта АС10 обусловлено микронеоднородностью данных пород.

Состав цемента, его количество в поровом пространстве и насыщенность керна УВ в совокупности могут нивелировать электрическое сопротивление пласта в различных зонах насыщения, что может привести к искажению насыщенности коллектора в целом.

С целью повышения достоверности оценки насыщенности пород УВ пласта АС10, необходимо совокупное использование литолого-петрофизических и геофизических данных. Необходимо формировать системный подход для решения такого рода задач.

\section{Библиография}

1. Азаматов В.И. Исследование вопросов оценки запасов нефти крупных месторождений в связи с проектированием их разработки. - Автореф. дис. на соиск. ученой степени д-ра геол.минерал. наук. М., 1975, (МИНХиГП). -38 с.

2. Борисов Ю.П., Воинов В.В., Рябинина 3.К. Влияние неоднородности пластов на разработку нефтяных месторождений. Москва: «Недра», 1970. - 288 с.

3. Жданов М.А., Ованесов М.Г., Токарев М.А. Комплексный учет геологической неоднородности при анализе выработки нефтеотдачи. - Геология нефти и газа, 1974, № 3. - С. 19-23.

4. Изучение геологической неоднородности нефтяных залежей в связи с их разработкой / В.С. Мелик-Пашаев, И.М. Климушин, В.А. Бреев и др. - Труды ВНИИ. Москва, 1974, вып. LIX. - C. 3-12.

5. Ратников И.Б., Шульга Р.С., Романов Е.А. Интерпретация данных капиллярных исследований // Горные науки и технологии, 2016, № 4. - С. 24-39.

6. Ратников И.Б., Шульга Р.С., Романов Е.А., Бастриков С.Н. Анализ параметра пористости с привлечением элементов региональной петрофизики (электрофаций) и типа глинистости // Горные науки и технологии, 2016, № 2. - С. 50-65.

7. Семенов В.В., Морева Е.В., Ратников И.Б. Изучение неоднородных коллекторов на керне методом микропрофилирования // Геофизика, 2006, № 2. - С. 48-52.

8. Семенов В.В., Ратников И.Б., Сокова К.И. Новые технологии экспериментального изучения сложнопостроенных коллекторов // Актуальные вопросы петрофизики сложнопостроенных коллекторов / Под редакцией доктора геолого-минералогических наук И.Г. Шнурмана. - Краснодар: Просвещение-Юг, 2010. - С. 110-170. 


\section{References}

1. Azamatov V.I. Study of problems of major fields oil reserves estimation in relation with these fields development projects. - Abstract of the thesis for a doctoral degree in geology and mineralogy. M., 1975, (MINH\&GP) - 38 p.

2. Borisov Y.P., Voinov V.V., Ryabinina Z.K. Influence of formations heterogeneity on the oil fields development. Moscow: «Nedra», 1970, $288 \mathrm{p}$.

3. Zhdanov M.A., Ovanesov M.G., Tokarev M.A. Integrated assessment of geological heterogeneity at analysis of oil recovery depletion. - Oil and gas geology, 1974, No. 3. - pp. 19-23.

4. Study of geological heterogeneity of oil deposits in terms of their development / V.S. Melik-Pashaev, I.M. Klimushin, V.A. Breiev, et.al. Proceedings of VNII, Moscow, 1974, issue LIX - pp. 3-12.

5. Ratnikov I.B., Shulga R.S., Romanov E,A. Interpretation of capillary study data // Rock sciences and technologies, 2016, No.4, pp.24-39.

6. Ratnikov I.B., Shulga R.S., Romanov E.A., Bastrikov S.N. Analysis of porosity parameter with involvement of regional petrophysics elements (electrofacies) and the type of shaliness // Rock Sciences and Technologies, 2016, No. 2, pp. 50-65.

7. Semyonov V.V., Moreva E.V., Ratnikov I.B. Study of heterogeneous reservoirs on cores using the microprofiling method // Geophysics, 2006, No.2, pp. 48-52.

8. Semoynov V.V., Ratnikov I.B., Sokova K.I., Advanced technologies of experimental study of complex geology structure reservoirs // Actual issues of complex geology structure reservoirs petrophysics / Edited by I.G. Shnurman, Doctor of Geology and Mineralogy. - Krasnodar: EducationSouth, 2010. - pp. 110-170. 